\title{
S'approprier le Louvre : deux siècles de relations muséales en France et en Europe
}

\section{Cecilia Hurley-Griener}

\section{OpenEdition Journals}

Édition électronique

URL : http://journals.openedition.org/cel/838

DOI : $10.4000 / \mathrm{cel} .838$

ISSN : 2262-208X

\section{Éditeur}

École du Louvre

\section{Référence électronique}

Cecilia Hurley-Griener, « S'approprier le Louvre : deux siècles de relations muséales en France et en Europe ", Les Cahiers de l'École du Louvre [En ligne], 11 | 2017, mis en ligne le 26 octobre 2017, consulté le 24 septembre 2020. URL : http://journals.openedition.org/cel/838 ; DOl : https://doi.org/10.4000/ cel.838

Ce document a été généré automatiquement le 24 septembre 2020.

\section{cc) $(1) \odot$}

Les Cahiers de l'École du Louvre sont mis à disposition selon les termes de la licence Creative Commons Attribution - Pas d'Utilisation Commerciale - Pas de Modification 4.0 International. 


\title{
S'approprier le Louvre : deux siècles de relations muséales en France et en Europe
}

\author{
Cecilia Hurley-Griener
}

1 Les neuf contributions rassemblées ici ont été présentées dans le cadre du premier atelier de troisième cycle organisé par l'École du Louvre, en collaboration avec le centre Dominique-Vivant-Denon au musée du Louvre. L'atelier était ouvert aux étudiants de troisième cycle de l'École du Louvre, ainsi qu'aux doctorants des établissements partenaires. Nous avons accueilli des participants inscrits à l'École du Louvre et aux universités de Lille 3, Neuchâtel, Paris 1 Panthéon-Sorbonne, Paris Nanterre, Poitiers et enfin François-Rabelais de Tours.

2 En définissant le titre "S'approprier le Louvre "-qui renvoie également à l'axe de recherche en troisième cycle défini pour la période 2015-2018, Appropriation - nous avons espéré inciter une série de réflexions sur le musée du Louvre, et plus particulièrement sur le rôle qu'il a joué au titre de modèle. D'un point de vue architectural, de l'histoire des collections, de la mise en espace des objets, de l'organisation des départements, le Louvre constitue une référence importante, voire incontournable dans le monde muséal, en France, en Europe et outre-Atlantique. Cependant, le terme "appropriation » montre bien que l'enjeu consiste à étudier la manière dont un modèle est perçu, transformé, adapté et parfois nié par ceux et celles qui s'en inspirent. Les études de cas présentées ici proposent quelques pistes d'analyse de ces rapports complexes.

3 Le séminaire a dû son succès à la qualité des débats tout au long des séances ; de grands spécialistes ont accepté de participer activement aux discussions. Que soient remerciés ici : Alain Bonnet, Geneviève Bresc-Bautier, Marie-Claude Chaudonneret, Dominique de Font-Réaulx, Jean-Philippe Garric, Chantal Georgel, Sylvie Guichard, Laurent Haumesser, Sophie Jugie, Odile Nouvel, Sophie Picot-Bocquillon, Dominique Poulot, Rocco Rante, Alice Thomine-Berrada et Christine Walter. 
Cecilia Hurley-Griener, au nom des organisatrices et collaboratrices de l'atelier : Claire Barbillon, Anne Krebs, Marie-Claire Le Bourdellès, Françoise Mardrus, Néguine Mathieux, Anne-Solène Rolland.

\section{AUTEUR \\ CECILIA HURLEY-GRIENER}

Membre de l'équipe de recherche HDR et chercheuse rattachée aux collections spéciales à l'université de Neuchâtel en Suisse, Cecilia Hurley-Griener a soutenu au sein de cette dernière une thèse consacrée aux Antiquités nationales d'Aubin-Louis Millin et leur place dans les cultures antiquaires et patrimoniales en France à la fin du XVIII ${ }^{\mathrm{e}}$ siècle (Monuments for people, Brepols, 2013). Elle a ensuite défendu son HDR, intitulée Le musée comme livre à l'université LumièreLyon II, avec un mémoire inédit sur les salles de chefs-d'œuvre dans la culture muséale en Europe au cours du XIX ${ }^{e}$ siècle. À l'École du Louvre, elle enseigne l'histoire des dispositifs muséographiques. Elle travaille aussi sur des catalogues, ayant co-édité avec Claire Barbillon Le Catalogue dans tous ses états (École du Louvre / Documentation française, 2015). Elle s'intéresse également à l'histoire de la peinture au XIX ${ }^{\mathrm{e}}$ siècle et a assuré le commissariat scientifique d'une exposition consacrée à Maximilien de Meuron et l'art de son temps au Musée d'art et d'histoire de Neuchâtel en 2016.

$* * *$

Member of the Research group at the École du Louvre and head of special collections at the University of Neuchâtel, Cecilia Hurley-Griener wrote her PhD thesis at the University of Neuchâtel on Aubin-Louis Millin and his Antiquités nationales [1790-1798] (Monuments for the people, Brepols, 2013). She recently completed her HDR at Lyon II University, with a study on masterpiece rooms in European museums during the nineteenth and twentieth centuries. At the École du Louvre she teaches the history of museum display. She has co-edited, with Claire Barbillon, a conference on catalogue Le Catalogue dans tous ses états (École du Louvre / Documentation française, 2015). She was the scientific curator for an exhibition on Maximilien de Meuron at the Musée d'Art et d'Histoire in Neuchâtel in 2016. 